\title{
Animal Testing Alternative
}

National Cancer Institute

\section{Source}

National Cancer Institute. Animal Testing Alternative. NCI Thesaurus. Code C15182.

Any method or technique that eliminates the use of animals in experiments, research, and testing. 